\title{
Activated Carbon for Dyes Removal: Modeling and Understanding the Adsorption Process
}

\author{
Y. El maguana $(\mathbb{D}$, N. Elhadiri, M. Benchanaa, and R. Chikri \\ Research Laboratory on Materials Reactivity and Process Optimization «REMATOP», Department of Chemistry, \\ Faculty of Science Semlalia, Cadi Ayyad University, B.P. 2390, Marrakech, Morocco
}

Correspondence should be addressed to Y. El maguana; youssefelmaguana@gmail.com

Received 7 June 2020; Revised 16 August 2020; Accepted 1 September 2020; Published 14 September 2020

Academic Editor: José M. G. Martinho

Copyright $(92020$ Y. El maguana et al. This is an open access article distributed under the Creative Commons Attribution License, which permits unrestricted use, distribution, and reproduction in any medium, provided the original work is properly cited.

Batch adsorption experiments have been conducted to investigate the removal of methyl orange from aqueous solution by an activated carbon prepared from prickly pear seed cake by phosphoric acid activation. The adsorption process has been described by using kinetic and isotherm models. The kinetic of adsorption was examined by pseudo-first-order, pseudo-second-order, and intraparticle diffusion models. Adsorption isotherm was modeled using Langmuir, Freundlich, Temkin and Dubinin-Radushkevich isotherms. The adsorption process of methyl orange was well explained by the pseudo-second-order model and Freundlich isotherm. Also, pseudo- $n$-order model has been applied to estimate the order of adsorption kinetic and it was found equal to 2 which confirm the good accuracy of the pseudo-second order. Moreover, Dubinin-Radushkevich isotherm reveals that the adsorption of methyl orange onto activated carbon was a physisorption process in nature. The adsorption capacity of activated carbon was found to be $336.12 \mathrm{mg} / \mathrm{g}$ at temperature $20^{\circ} \mathrm{C}$ and $\mathrm{pH} \sim 7$. These results demonstrated that the prickly pear seed cake is a suitable precursor for the preparation of appropriate activated carbon for dyes removal from aqueous solution.

\section{Introduction}

Industrial liquid effluents contain a wide variety of chemicals which affect, if discharged without any treatment, rivers, seas, lakes, and groundwater and therefore cause environmental pollution and harmful effects on human and animal health even in low concentrations [1-4]. Among these chemicals, the dyes used in several sectors such as textiles, cosmetics, plastics, pigments units, leather, and paper industries have been considered as the primary pollutant due to their stability and low biodegradability [3]. Indeed, significant quantities of dyes are released into the environment by colored textile wastewater. Approximately, it is estimated that 10 to $15 \%$ is lost in the effluent during the dyeing process [5]. Consequently, the scientific community has focused their research on the development effective dyes removal techniques. In recent years, Considerable interest has been focused on the adsorption technique for dyes removal from solutions using various adsorbent such as activated carbon [6-8], clays [9, 10], siliceous material [11, 12], zeolites [13, 14], alumina [15], and hybrid materials [16, 17]. The adsorption is highly effective technique for dyes removal from wastewater. The major advantages of adsorption process are its relative simplicity, low cost, and possible regeneration of the adsorbent [3].

Activated carbon is well known as an adsorbent characterized by its large specific surface, its porous structure, and its thermostability, which is extensively used in a variety of applications such as removal of pollutants and odor from liquid and gaseous phases, medical uses, catalysis, gas storage, electrode materials in electrochemical devices, and removal of organic pollutants from drinking water and in the waste water treatment $[7,18-24]$. Adsorption on activated carbon has been found to be a very efficient technique for removal of dyes from wastewater in terms of capability for efficiently adsorbing a broad range of pollutants, fast adsorption kinetics, simplicity of design, and low cost [25-27]. In recent years, there has been increasing interest in the research of the production of activated carbons from the agricultural byproducts and industrial wastes for dyes 
removal $[8,28-32]$. The utilization of those biomass wastes has a positive impact in environment protection by reducing solid wastes and also the production of low-cost activated carbons with high added value which can reduce contaminants in wastewater at a reasonable cost.

In industrial scale, the adsorbent and liquid effluent are in contact with each other for a given time, therefore, predicating the equilibrium time and the rate of adsorption is of paramount importance. For that, the kinetic and equilibrium properties of the adsorbate/adsorbent system have been investigated to understand the characteristic of the adsorption behavior. The modeling of adsorption processes is usually carried out using well-established adsorption kinetic and isotherm models. Adsorption kinetics models provide invaluable information on the controlling mechanisms of adsorption process. The overall adsorption process may be controlled by either external or film diffusion, pore diffusion and adsorption on the pore surface, or a combination of more than one step. The adsorption isotherm describes the interaction between the adsorbate molecules and the adsorbent when the system reaches the equilibrium. It provides the qualitative information on the nature of adsorbate-adsorbent surface interactions and could be used to evaluate the adsorption capacity.

The aim of this work is to investigate both kinetic and equilibrium adsorption of methyl orange (MO) onto an activated carbon prepared from prickly pear seed cake by phosphoric acid activation. Methyl orange was chosen as an adsorbate to evaluate the adsorption characteristics of activated carbon and also serves as a model compound for adsorption of organic contaminants from aqueous solution.

\section{Materials and Methods}

2.1. Materials. Activated carbon prepared by El maguana et al. [33] was sieved to obtain particles size less than $100 \mu \mathrm{m}$. Methyl orange used as adsorbate in the present study and without further purification was supplied by Merck. A stock solution was prepared by dissolving the weighted quantity of methyl orange in distilled water. Then solutions of desired concentrations were prepared by diluting stock solution with distilled water.

The structure of methyl orange is given by

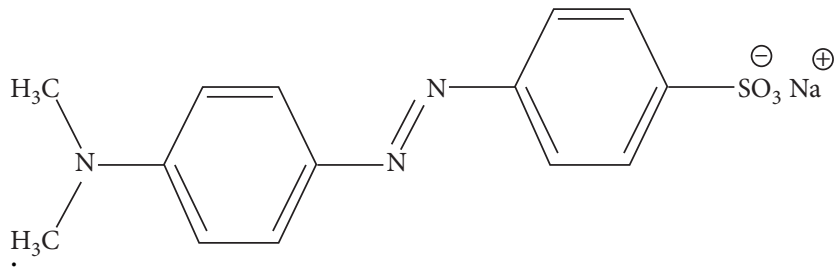

2.2. Adsorption Experiments. Batch adsorption experiments have been conducted to evaluate the efficiency of activated carbon to remove methyl orange dye from aqueous solution. The experiments were performed in flasks containing a defined amount of activated carbon and $100 \mathrm{~cm}^{3}$ of desired concentration of methyl orange solution. The suspensions were mixed on a shaker at $180 \mathrm{rpm}$ at $20^{\circ} \mathrm{C}$ during a given time and separated with centrifuge. After adsorption, the residual concentration of methyl orange was determined by spectrophotometric method (UV-3100PC Spectrophotometer) at $462 \mathrm{~nm}$. The amount of adsorption at equilibrium $\left(q_{\mathrm{e}}\right)$ was defined as the amount of adsorbate per Gram of adsorbent (in $\mathrm{mg} / \mathrm{g}$ ) and was calculated using the following equation:

$$
q_{\mathrm{e}}=\frac{C_{0}-C_{\mathrm{e}}}{m} \times V
$$

The percentage removal $(\mathrm{R} \%)$ of the methyl orange at equilibrium was calculated using the following relationship:

$$
R \%=\frac{C_{0}-C_{\mathrm{e}}}{C_{0}} \times 100,
$$

where $C_{0}$ and $C_{\mathrm{e}}$ (in $\mathrm{mg} / \mathrm{L}$ ) are the initial and equilibrium concentrations in aqueous solution respectively, $\mathrm{V}(\mathrm{L})$ is the volume of the solution, and $\mathrm{m}(\mathrm{g})$ is the mass of the adsorbent.

\section{Results and Discussion}

Activated carbon used in this study was prepared from prickly pear seed cake by phosphoric acid activation [33]. The authors reported that the obtained activated carbon is effective for removing cationic dyes such as methylene blue from aqueous solution. FTIR analysis indicated the presence of various functional groups (oxygen functions and phosphorus compounds) on the surface of the obtained activated carbon, which gave the adsorbent an acidic surface $\left(\mathrm{pH}_{\mathrm{PZC}}=3.8\right)$. Moreover, the adsorption process was well described by the pseudo-second-order model and Freundlich isotherm. The adsorption capacity of the prepared activated carbon for methylene blue at temperature $20^{\circ} \mathrm{C}$ and $\mathrm{pH} \sim 7$ was found to be $260 \mathrm{mg} / \mathrm{g}$ [33]. To test the performance of the prepared activated carbon in the removal of anionic dyes from aqueous solution, methyl orange was chosen as a model adsorbate. The adsorption performance was evaluated by kinetic and isotherm studies.

3.1. Adsorption Kinetic. To investigate the adsorption kinetic, the amount of methyl orange adsorbed by the activated carbon is studied at $\mathrm{pH} \sim 7$ for an adsorbent dose of $0.2 \mathrm{~g} / \mathrm{L}$ and an initial methyl orange concentration of $100 \mathrm{mg} / \mathrm{L}$ at $20^{\circ} \mathrm{C}$. Figure 1 shows the effect of contact time on the adsorption capacity of the activated carbon prepared from prickly pear seed cake for methyl orange, at room temperature. It reveals that the adsorbed amount increased with contact time at the initial stage of adsorption and reached equilibrium in $120 \mathrm{~min}$. The adsorption process of methyl orange was rapid at the beginning of the process due to the availability of active sites on the exterior surfaces and after the saturation of those active sites, the methyl orange entered to the pores of the adsorbent with a slower rate to reach the equilibrium time [33]. The amount of methyl orange removed by adsorption onto the activated carbon at the equilibrium time was $194 \mathrm{mg} / \mathrm{g}$.

Adsorption kinetics models provide invaluable information on the controlling mechanisms of adsorption 


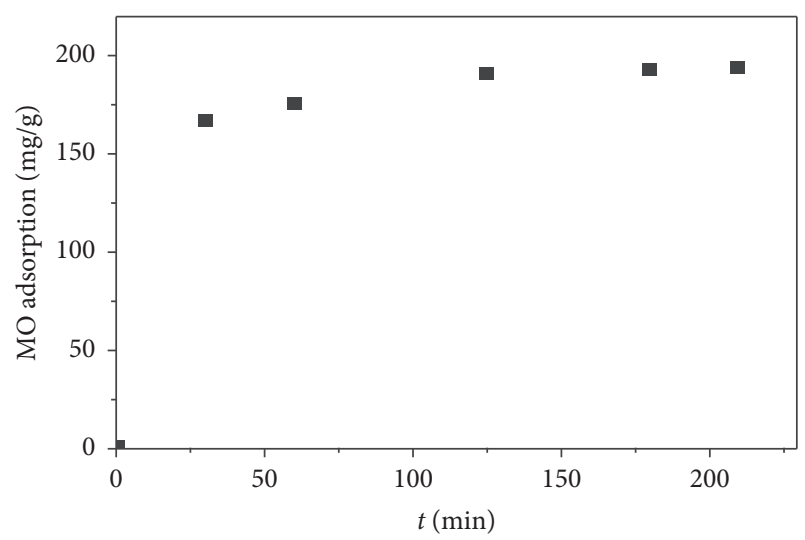

Figure 1: Effect of contact time on the MO adsorption onto activated carbon $\left(C_{0}=100 \mathrm{mg} / \mathrm{L}\right.$; adsorbent dose $=0.2 \mathrm{~g} / \mathrm{L} ; \mathrm{pH} \sim 7$; $T=20^{\circ} \mathrm{C}$.

process [34]. The overall adsorption process may be controlled by either external or film diffusion, pore diffusion and adsorption on the pore surface, or a combination of more than one step [34]. In order to predict the mechanism of the adsorption process of methyl orange onto the activated carbon, the experimental data were fitted with different kinetic models. In a first step, the experimental kinetic data were fitted by pseudo-first-order and pseudo-second-order kinetic models. We employed pseudo-first-order and pseudo-second-order models in their nonlinear forms to determine the kinetic parameters because, in this way, the kinetic parameters are predicted better than in the linearized forms of these models [33, 35].

The nonlinear form of pseudo-first-order model [36] is given by the following equation:

$$
q_{t}=q_{\mathrm{e}}\left(1-e^{-k_{1} t}\right) .
$$

The nonlinear form of pseudo-second-order model [37] is given as follows:

$$
q_{t}=\frac{k_{2} q_{\mathrm{e}}^{2} t}{1+k_{2} q_{\mathrm{e}} t}
$$

where $q_{\mathrm{e}}(\mathrm{mg} / \mathrm{g})$ is the adsorption amount at equilibrium, $q_{\mathrm{t}}(\mathrm{mg} / \mathrm{g})$ is the adsorption amount at time $t(\mathrm{~min})$, and $k_{1}$ $(1 / \mathrm{min})$ and $k_{2}(\mathrm{~g} / \mathrm{mg} \mathrm{min})$ are the adsorption rate constants of pseudo-first-order and pseudo-second-order models, respectively. Kinetic parameters, $q_{\mathrm{e}}, k_{1}$, and $k_{2}$, can be calculated from the plots of $q_{\mathrm{e}}$ versus $t$.

The validity of these models was evaluated by the coefficient of regression $R^{2}$ and by the normalized standard deviation $\Delta q(\%)$, which is defined as follows:

$$
\Delta q(\%)=100 \sqrt{\frac{\sum\left[\left(q_{\exp }-q_{\mathrm{cal}}\right) / q_{\mathrm{exp}}\right]^{2}}{N-1}},
$$

where $q_{\exp }$ and $\mathrm{q}_{\mathrm{cal}}$ are the experimental and calculated equilibrium adsorption capacity value, respectively, and $N$ is the number of data points.

Figure 2 shows the plots for pseudo-first-order and pseudo-second-order models. The calculated values of $k_{1}, k_{2}, q_{\mathrm{e}}$,

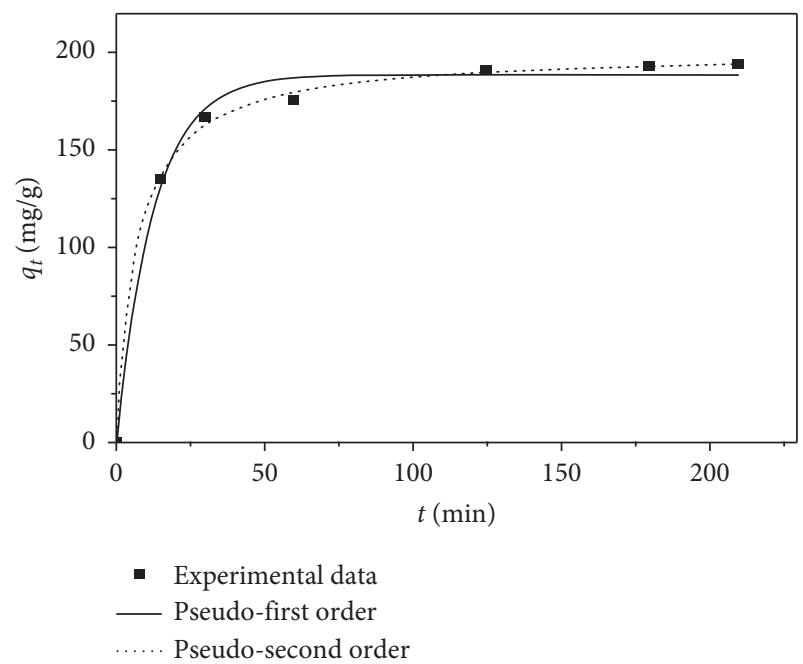

Figure 2: Nonlinear fits of pseudo-first-order and pseudosecond-order kinetics for MO adsorption onto activated carbon $\left(C_{0}=100 \mathrm{mg} / \mathrm{L}\right.$; adsorbent dose $\left.=0.2 \mathrm{~g} / \mathrm{L} ; \mathrm{pH} \sim 7 ; T=20^{\circ} \mathrm{C}\right)$.

correlation coefficient $\left(R^{2}\right)$, and normalized standard deviation $\Delta q$ are presented in Table 1. It can be seen that both pseudofirst-order and pseudo-second-order models have a good fit to the experimental data $\left(R^{2}\right.$ greater than 0.99 and $\Delta \mathrm{q}$ lower than $5 \%)$. Moreover, the equilibrium adsorption capacities $\left(q_{e, \text { cal }}\right)$ calculated by the pseudo-first order and pseudo-second order are closer to the experimental value $\left(q_{\text {e,exp }}=194.08 \mathrm{mg} / \mathrm{g}\right)$. According to these results, we can say that both pseudo-firstorder and pseudo-second-order models could be used to describe the adsorption process of methyl orange onto activated carbon. However, $\Delta q$ for pseudo-second order was lower than that for pseudo-first order, thus suggesting an order kinetic greater than 1. Taking into account that the kinetic order can take a decimal value, the kinetic data were fitted with a pseudo$n$ order kinetic model [38] expressed as follows:

$$
q_{t}=q_{\mathrm{e}}\left[1-\left[1+(n-1) k_{n} t\right]^{1 / 1-n}\right],
$$

where $q_{\mathrm{e}}(\mathrm{mg} / \mathrm{g})$ is the adsorption amount at equilibrium, $q_{\mathrm{t}}(\mathrm{mg} / \mathrm{g})$ is the adsorption amount at time $t(\mathrm{~min})$, and $k_{\mathrm{n}}$ $(1 / \mathrm{min})$ is the adsorption rate constant of pseudo- $n$-order model.

The plot corresponding to the nonlinear fit of pseudo$n$-order kinetic model for methyl orange adsorption onto activated carbon is presented in Figure 3. The kinetic parameters obtained from the pseudo- $n$-order kinetic model are listed in Table 2. The results show that the values of $R^{2}$ and $\Delta q$ obtained by pseudo- $n$-order kinetic model are equal to those for pseudo-second order. Moreover, the equilibrium adsorption capacities $\left(q_{\mathrm{e}, \mathrm{cal}}\right)$ calculated by pseudo- $n$ order and pseudo-second-order kinetic models are similar and the value of $n$ is almost equal to $2(n=1.97)$. Therefore, the adsorption process of methyl orange on the activated carbon can be well described by pseudo-second-order model, suggesting that the boundary layer resistance was not the rate-limiting step [33]. So, if the pseudo-first-order kinetic parameters are closer to those for pseudo-second order, then we cannot deduce the kinetic model which can 
Table 1: Pseudo-first-order and pseudo-second-order kinetic parameters $\left(C_{0}=100 \mathrm{mg} / \mathrm{L}\right.$; adsorbent dose $\left.=0.2 \mathrm{~g} / \mathrm{L} ; \mathrm{pH} \sim 7 ; T=20^{\circ} \mathrm{C}\right)$.

\begin{tabular}{lcccccccc}
\hline \multirow{2}{*}{$q_{\mathrm{e}, \exp }(\mathrm{mg} / \mathrm{g})$} & \multicolumn{3}{c}{ Pseudo-first order } & \multicolumn{3}{c}{ Pseudo-second order } \\
& $q_{\mathrm{e}, \mathrm{cal}}(\mathrm{mg} / \mathrm{g})$ & $k_{1}(1 / \mathrm{min})$ & $R^{2}$ & $\Delta q(\%)$ & $q_{\mathrm{e}, \mathrm{cal}}(\mathrm{mg} / \mathrm{g})$ & $k_{2}(\mathrm{~g} / \mathrm{mg} / \mathrm{min})$ & $R^{2}$ & $\Delta q(\%)$ \\
\hline 194.08 & 188.42 & $7.9510^{-2}$ & 0.990 & 3.83 & 200.34 & 7.15 & $10^{-4}$ & 0,998 \\
\hline
\end{tabular}

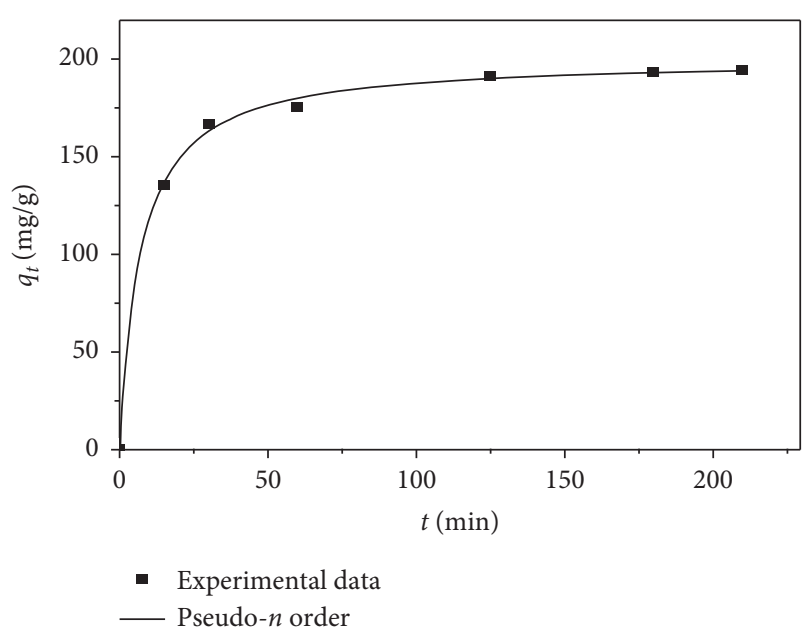

FIGURE 3: Nonlinear fit of pseudo- $n$-order kinetic model for MO adsorption onto activated carbon $\left(C_{0}=100 \mathrm{mg} / \mathrm{L}\right.$; adsorbent dose $=0.2 \mathrm{~g} / \mathrm{L} ; \mathrm{pH} \sim 7 ; T=20^{\circ} \mathrm{C}$ ).

TABle 2: Pseudo- $n$-order kinetic parameters $\left(C_{0}=100 \mathrm{mg} / \mathrm{L}\right.$; adsorbent dose $=0.2 \mathrm{~g} / \mathrm{L} ; \mathrm{pH} \sim 7 ; \mathrm{T}=20^{\circ} \mathrm{C}$ ).

\begin{tabular}{|c|c|c|c|c|c|}
\hline \multirow[b]{2}{*}{$q_{\mathrm{e}, \exp }(\mathrm{mg} / \mathrm{g})$} & \multicolumn{5}{|c|}{ Pseudo- $n$ order } \\
\hline & $q_{\mathrm{e}, \mathrm{cal}}(\mathrm{mg} / \mathrm{g})$ & $k_{\mathrm{n}}(1 / \mathrm{min})$ & $n$ & $R^{2}$ & $\Delta q(\%)$ \\
\hline 194.08 & 199.78 & $14.0710^{-2}$ & 1.97 & 0.998 & 1.59 \\
\hline
\end{tabular}

be used to predict the mechanism of the adsorption process. Hence, it appears that the use of a general kinetic model (pseudo- $n$ order) with no preset reaction order is advisable when $R^{2}$ and $\Delta q$ of pseudo-first-order and pseudo-second-order models are comparable.

The possibility of intraparticle diffusion resistance was explored by using the intraparticle diffusion model proposed by Weber and Morris [39], expressed as follows:

$$
q_{t}=k_{\mathrm{id}} t^{1 / 2}+c,
$$

where $q_{t}(\mathrm{mg} / \mathrm{g})$ is the adsorption amount at time $t(\mathrm{~min}), k_{\mathrm{id}}$ $\left(\mathrm{mg} / \mathrm{g} / \mathrm{min}^{1 / 2}\right)$ is the adsorption rate constant of intraparticle diffusion model, and $c$ is a constant related to the thickness of the boundary layer.

If the plot of $q_{t}$ versus $t^{1 / 2}$ is linear and passes through the origin, then intraparticle diffusion is the sole rate-limiting step of the adsorption process. Figure 4 shows the plot of the intraparticle diffusion model, which is not linear and did not pass through the origin, indicating that intraparticle diffusion was not the only rate-limiting step of the adsorption process of methyl orange onto the activated carbon, but also other mechanisms may control the rate of the adsorption, all of which may be operating simultaneously $[8,34,40]$. The

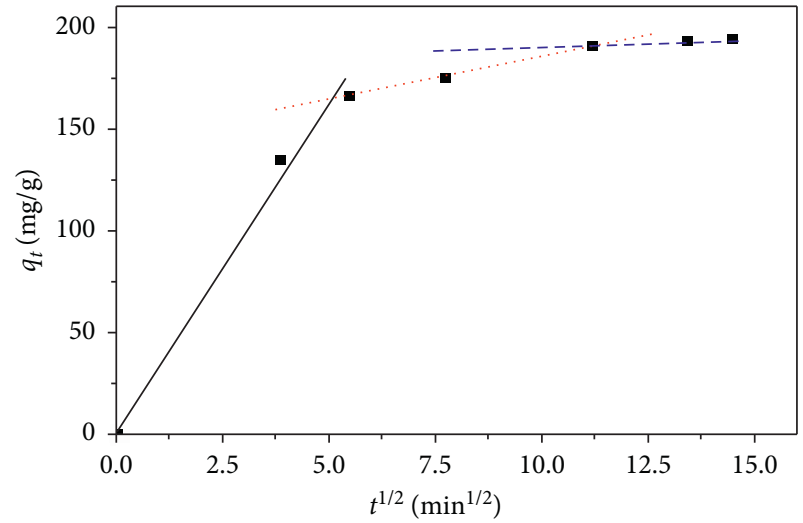

- Experimental data

FIgUre 4: Plot of the intraparticle diffusion model for $\mathrm{MO}$ adsorption onto sugar scum $\left(C_{0}=100 \mathrm{mg} / \mathrm{L}\right.$; adsorbent dose $=0.2 \mathrm{~g} / \mathrm{L}$; $\mathrm{pH} \sim 7 ; T=20^{\circ} \mathrm{C}$.

first portion of the plot is attributed to the transport of solute from bulk solution through liquid film to the adsorbent exterior surface. Thereafter, the second part is ascribed to the intraparticle diffusion as slower process. In fact, the slope of the linear portion indicates the rate of the adsorption process: the lower slope corresponds to a slower adsorption process $[34,41]$. Thus, the rate of the diffusion of methyl orange molecules through boundary layer film in the initial stage of the adsorption process was faster than the rate of the intraparticle diffusion because the slope of the first linear portion was higher than of the second linear portion. Initially, the methyl orange molecules are quickly adsorbed onto the surface of the activated carbon, and when saturation is reached, the methyl orange molecules are diffused into the interior of adsorbent particles [34]. Finally, the last portion is attributed to the final equilibrium stage for which the intraparticle diffusion slows down due to the low concentration dye in the aqueous solution [42].

3.2. Equilibrium Adsorption. Adsorption equilibrium is established between the adsorbed molecules and the adsorbent surface when an adsorbate is in contact with the adsorbent. The equilibrium relationship between the adsorbed amount of adsorbate $\left(q_{\mathrm{e}}\right)$ and the residual adsorbate concentration $\left(C_{\mathrm{e}}\right)$ at constant temperature is described by the adsorption isotherm. This last is very useful for understanding the adsorption mechanism. In general, adsorption isotherms provide information on the affinity and the binding energy between the adsorbate and the adsorbent, on the adsorption capacity and on the surface phase which may be considered as a monolayer or multilayer. All this information can be extracted from equilibrium 
isotherm models describing the adsorption process. Several isotherm models are presented in the literature, which permit a better understanding of the adsorption phenomenon of chemical species on the adsorbent. The modeling of the adsorption isotherms consists in describing the experimental data using theoretical or empirical mathematical equations and allowing determination of isotherm parameters to compare the efficiency of different adsorbents.

To investigate the adsorption isotherm, the adsorption capacity of the activated carbon prepared from prickly pear seed cake for methyl orange is studied at temperature $20^{\circ} \mathrm{C}$ and $\mathrm{pH} \sim 7$ for an adsorbent dose of $1 \mathrm{~g} / \mathrm{L}$. Figure 5 shows the adsorption isotherm of methyl orange onto the activated carbon which indicates a significant adsorption at low concentrations. According to Giles classification [43], this isotherm displayed an $\mathrm{H}$ curve pattern, indicating that the methyl orange and activated carbon have a high affinity.

In the first step, the experimental data of adsorption isotherm were fitted to the Langmuir and Freundlich models to find which one can be used to describe the adsorption process of methyl orange onto the surface of the activated carbon. Langmuir equation assumes the monolayer adsorption on a homogenous surface without interaction between adsorbates [44], while the Freundlich isotherm was based on the assumption of the multilayer adsorption on heterogeneous surface [45].

The Langmuir isotherm equation is expressed as follows:

$$
q_{\mathrm{e}}=\frac{q_{\mathrm{m}} \cdot K_{\mathrm{L}} \cdot C_{\mathrm{e}}}{1+K_{\mathrm{L}} \cdot C_{\mathrm{e}}} .
$$

The Freundlich isotherm equation is given as follows:

$$
q_{\mathrm{e}}=K_{\mathrm{F}} C_{\mathrm{e}}^{1 / n}
$$

where $C_{\mathrm{e}}(\mathrm{mg} / \mathrm{L})$ is the equilibrium concentration of adsorbate, $q_{\mathrm{e}}(\mathrm{mg} / \mathrm{g})$ is the amount of adsorption at the equilibrium, $q_{\mathrm{m}}(\mathrm{mg} / \mathrm{g})$ is the monolayer adsorption capacity, $\mathrm{n}$ is the Freundlich intensity constant, and $K_{\mathrm{L}}$ and $K_{\mathrm{F}}$ are the Langmuir and Freundlich constants, respectively.

Figure 6 shows the Freundlich and Langmuir curves generated using (8) and (9). It can be seen from this figure that the adsorption isotherm of methyl orange onto the activated carbon was well described by the Freundlich equation. Calculated parameters of Langmuir and Freundlich isotherms along with $R^{2}$ values, obtained by the nonlinear fitting method, are listed in Table 3. Via comparison of the $R^{2}$ values, Freundlich equation represents a better fit of equilibrium experimental data than Langmuir. Therefore, the adsorption process of methyl orange onto the activated carbon can be described more appropriately by the Freundlich isotherm, indicating the multilayer adsorption on the heterogeneous surface with a different energy distribution. Freundlich constant, $n$, is a measure of adsorption intensity. As seen from Table 3 , a value of $1 / n$ was found between 0 and 1 , indicating the favorable adsorption of methyl orange on the activated carbon [33].

The experimental data of the adsorption isotherm were also fitted to Temkin isotherm equation to approach

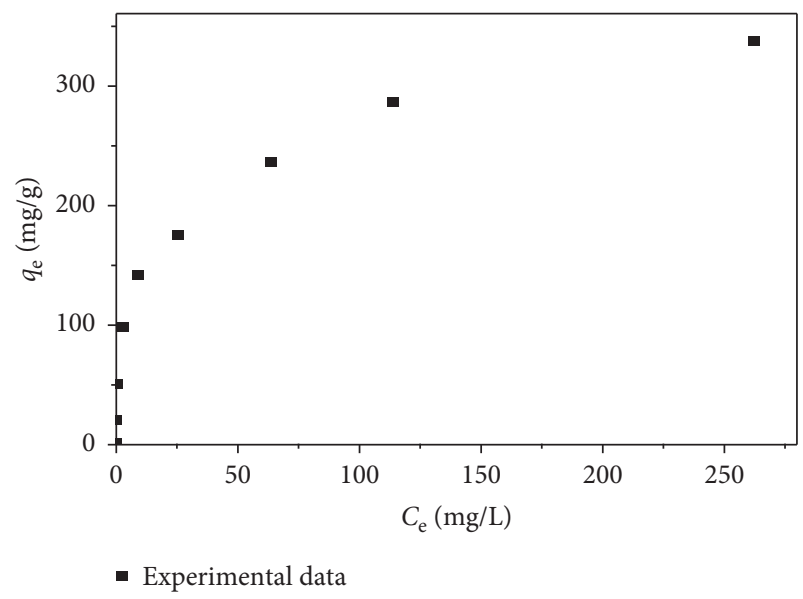

FIgURE 5: Adsorption isotherm of MO onto activated carbon $\left(t_{\text {contact }}=2 \mathrm{~h}\right.$; adsorbent dose $\left.=1 \mathrm{~g} / \mathrm{L} ; \mathrm{pH} \sim 7 ; T=20^{\circ} \mathrm{C}\right)$.

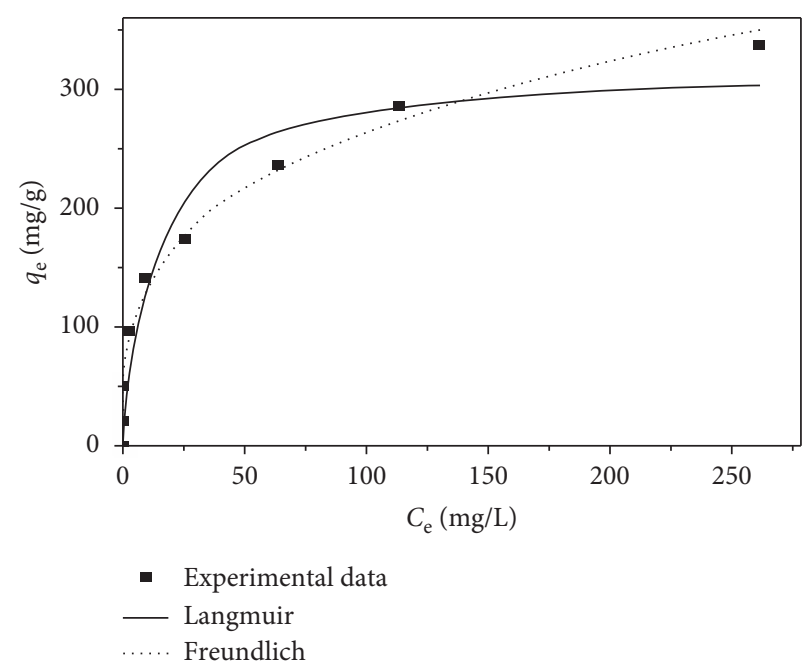

FIGURE 6: Nonlinear fits of the Langmuir and Freundlich isotherms for $\mathrm{MO}$ adsorption onto activated carbon $\left(t_{\text {contact }}=2 \mathrm{~h}\right.$; adsorbent dose $=1 \mathrm{~g} / \mathrm{L} ; \mathrm{pH} \sim 7 ; \mathrm{T}=20^{\circ} \mathrm{C}$ ).

TABle 3: Langmuir and Freundlich isotherm parameters $\left(t_{\text {contact }}=2 \mathrm{~h}\right.$; adsorbent dose $\left.=1 \mathrm{~g} / \mathrm{L} ; \mathrm{pH} \sim 7 ; \mathrm{T}=20^{\circ} \mathrm{C}\right)$.

\begin{tabular}{lccccc}
\hline \multicolumn{3}{c}{ Langmuir } & \multicolumn{4}{c}{ Freundlich } \\
\hline$q_{\mathrm{m}}(\mathrm{mg} / \mathrm{g})$ & $K_{\mathrm{L}}(\mathrm{L} / \mathrm{mg})$ & $R^{2}$ & $1 / n$ & $\mathrm{KF}\left((\mathrm{mg} / \mathrm{g})(\mathrm{L} / \mathrm{mg})^{1 / n}\right)$ & $R^{2}$ \\
319.06 & 0.0748 & 0.93 & 0.29 & 69.82 & 0,99 \\
\hline
\end{tabular}

energetic aspects. Temkin isotherm is based on the assumption that the heat of adsorption of all the molecules in the layer decreased linearly with coverage and adsorption is characterized by a uniform distribution of binding energies [46].

The Temkin isotherm equation is expressed as

$$
q_{\mathrm{e}}=\frac{\mathrm{RT}}{b} \ln \left(K_{\mathrm{T}} C_{\mathrm{e}}\right)
$$


where $q_{\mathrm{e}}(\mathrm{mg} / \mathrm{g})$ is the amount of adsorption at the equilibrium, $C_{\mathrm{e}}(\mathrm{mg} / \mathrm{L})$ is the equilibrium concentration of adsorbate, $T(\mathrm{~K})$ is the temperature, $R$ is the universal gas constant, and $K_{\mathrm{T}}$ is the equilibrium binding constant corresponding to the maximum binding energy. The constant $b$ $(\mathrm{J} / \mathrm{mol})$ is related to the heat of adsorption. The Temkin isotherm parameters were obtained by plotting $q_{\mathrm{e}}$ versus $C_{\mathrm{e}}$, shown in Figure 7 and summarized in Table 4. According to the $R^{2}$ value, the Temkin isotherm model did not fit well with the experimental data indicating the energetic heterogeneity of the adsorption sites.

Besides the Langmuir, Freundlich, and Temkin models, the Dubinin-Radushkevich isotherm model was also employed for the estimation of the adsorption energy $(E)$ and further finding the nature of the adsorption [41, 47]. Its equation is given as follows:

$$
q_{\mathrm{e}}=q_{\mathrm{m}} \exp \left[-K_{\mathrm{DR}}\left[\mathrm{RT} \ln \left(1+\frac{1}{C_{\mathrm{e}}}\right)\right]^{2}\right],
$$

where $q_{\mathrm{e}}(\mathrm{mg} / \mathrm{g})$ is the amount of adsorption at the equilibrium, $C_{\mathrm{e}}(\mathrm{mg} / \mathrm{L})$ is the equilibrium concentration of adsorbate, $q_{\mathrm{m}}$ is the monolayer adsorption capacity, $\mathrm{K}_{\mathrm{DR}}$ is the $\mathrm{D}-\mathrm{R}$ constant which gives the adsorption energy (E), $T(\mathrm{~K})$ is the temperature, and $R$ is the universal gas constant. The adsorption energy can be computed using the following relationship:

$$
E=\frac{1}{\sqrt{2 B}}
$$

The adsorption energy $(E)$ value gives information about adsorption mechanism and more specifically its physical or chemical nature. When $E$ is lower than $8 \mathrm{~kJ} / \mathrm{mol}$, the type of adsorption can be explained by physisorption and it can be controlled by ion-exchange or chemical adsorption when $E$ is higher than $8 \mathrm{~kJ} / \mathrm{mol}[48]$.

Figure 8 shows the fitting curve of Dubinin-Radushkevich isotherm and the obtained parameters are listed in Table 4 . The calculated adsorption energy $(E=0.57 \mathrm{~kJ} / \mathrm{mol})$ reveals that the type of adsorption of methyl orange onto activated carbon can be explained by physisorption, indicating that the adsorption is illustrated by the formation of week physical attraction forces, such as hydrogen-bonding and van der Waals forces, between adsorbate molecules and solid surface, and thus adsorption is reversible. This result indicates that the adsorption of methyl orange onto the surface of the prepared activated carbon is a multilayer adsorption which confirms that this process follows the Freundlich isotherm.

The results of the previous [33] and present study showed that the activated carbon prepared from prickly pear seed cake by phosphoric acid activation is effective for removing cationic and anionic dyes such as methylene blue and methyl orange from aqueous solution. This can be explained by the presence of a variety of functional groups on the adsorbent surface, which have enhanced the adsorption capacity [33]. The activated carbon simultaneously

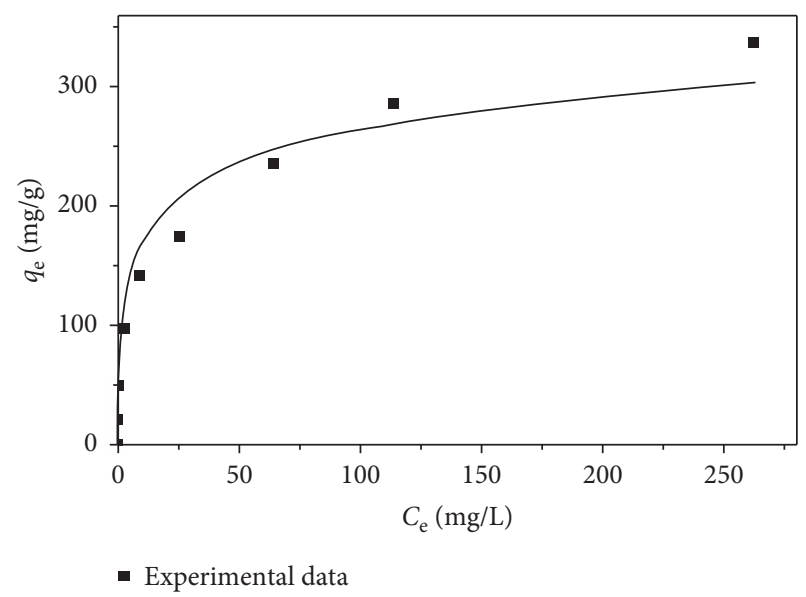

FIgURE 7: Nonlinear fit of the Temkin isotherm for MO adsorption onto activated carbon $\left(t_{\text {contact }}=2 \mathrm{~h}\right.$; adsorbent dose $=1 \mathrm{~g} / \mathrm{L} ; \mathrm{pH} \sim 7$; $T=20^{\circ} \mathrm{C}$ ).

TABLE 4: Temkin and Dubinin-Radushkevich isotherm parameters $\left(t_{\text {contact }}=2 \mathrm{~h}\right.$; adsorbent dose $\left.=1 \mathrm{~g} / \mathrm{L} ; \mathrm{pH} \sim 7 ; \mathrm{T}=20^{\circ} \mathrm{C}\right)$.

\begin{tabular}{lcccccc}
\hline & Temkin & \multicolumn{5}{c}{ Dubinin-Radushkevich } \\
\hline $\mathrm{b}$ & $K_{\mathrm{T}}$ & \multirow{2}{*}{$R^{2}$} & $q_{\mathrm{m}}$ & $\mathrm{K}_{\mathrm{DR}}$ & $\mathrm{E}$ & $R^{2}$ \\
$(\mathrm{~J} / \mathrm{mol})$ & $(\mathrm{L} / \mathrm{mg})$ & & $\mathrm{mg} / \mathrm{g}$ & $\mathrm{mol}^{2} / \mathrm{kJ}$ & $\mathrm{kJ} / \mathrm{mol}$ & \\
59.66 & 6.09 & 0.95 & 193.80 & 1.53 & 0.57 & 0.84 \\
\hline
\end{tabular}

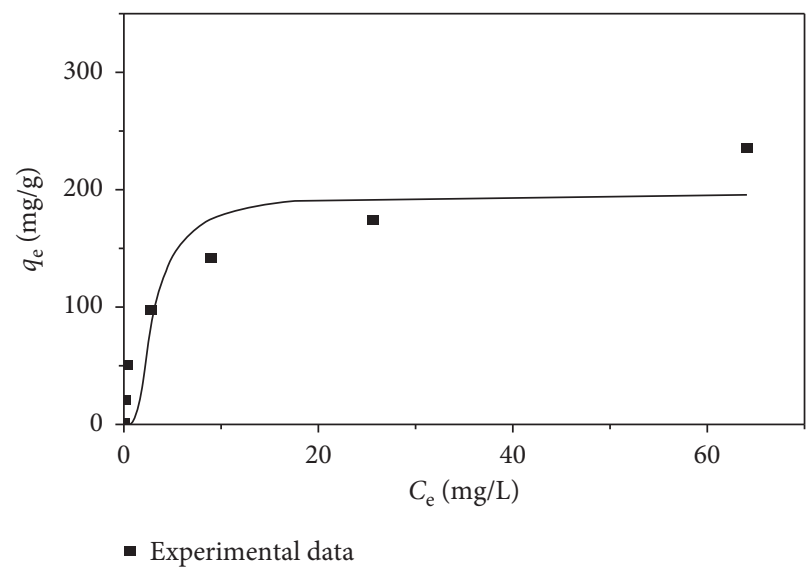

Figure 8: Nonlinear fit of the Dubinin-Radushkevich isotherm for MO adsorption onto activated carbon $\left(t_{\text {contact }}=2 \mathrm{~h}\right.$; adsorbent dose $=1 \mathrm{~g} / \mathrm{L} ; \mathrm{pH} \sim 7 ; T=20^{\circ} \mathrm{C}$ ).

presents acidic and basic sites able to fix cationic and anionic dyes by electrostatic interactions. The adsorption mechanism can also be explained by the interactions between delocalized $\pi$-electrons of the activated carbon surface and the free electrons of the dye molecules present in the aromatic rings and multiple bonds $[49,50]$. The adsorption capacities of MO onto various materials are given in Table 5 
TABle 5: Adsorption capacities of MO onto various materials.

\begin{tabular}{lcc}
\hline Adsorbents & $\mathrm{q}_{\mathrm{MO}}(\mathrm{mg} / \mathrm{g})$ & References \\
\hline Activated carbon nanotubes & 149 & {$[51]$} \\
Mesoporous carbon & 294.1 & 149.25 \\
Surfactants modified montmorillonite & 105.4 & {$[52]$} \\
Ammonium-functionalized silica nanoparticle & 333.33 & $163]$ \\
Lead oxide nanoparticles loaded activated carbon & 79.7 & {$[54]$} \\
Gold nanoparticles loaded on activated carbon & 349.7 & {$[55]$} \\
Activated carbon & 285 & {$[56]$} \\
Chitosan modified magnetic kaolin & 207 & {$[58]$} \\
Polyaniline/activated carbon composite & 336.12 & [59] \\
Chitosan microspheres & & This work \\
Activated carbon &
\end{tabular}

in order to evaluate the performance of the activated carbon prepared from prickly pear seed cake.

\section{Conclusion}

In this study, the use of the activated carbon prepared from prickly pear seed cake by thermo chemical process using phosphoric acid for the removal of methyl orange from aqueous solution has been studied. The kinetic of adsorbate-adsorbent interactions can be represented by the pseudo-second-order model. The equilibrium adsorption data are best fitted by the Freundlich model as compared to Langmuir and Temkin models. The adsorption capacity for methyl orange was found to be $336.12 \mathrm{mg} / \mathrm{g}$ at temperature $20^{\circ} \mathrm{C}$ and $\mathrm{pH} \sim 7$ indicating that the activated carbon may be an efficient adsorbent with great adsorptive capacity. Dubinin-Radushkevich isotherm reveals that the adsorption of methyl orange onto the activated carbon was a physisorption process in nature. The results demonstrated that the prickly pear seed cake is a suitable precursor for the preparation of an adequate activated carbon for dyes removal from industrial effluents.

\section{Data Availability}

All the data used to support the findings of this study are included within the article.

\section{Conflicts of Interest}

The authors declare that they have no conflicts of interest.

\section{Acknowledgments}

The authors are grateful to the Center of Analyses and Characterization (CAC) of University Caddy Ayyad, Morocco. Also, the authors also extend their appreciation to professors of REMATOP, LCOA, and REMINEX Managem Laboratories in Marrakech, Morocco.

\section{References}

[1] S. Kumar, C. Patra, S. Narayanasamy, and P. V. Rajaraman, "Performance of acid-activated water caltrop (Trapa natans) shell in fixed bed column for hexavalent chromium removal from simulated wastewater," Environmental Science and Pollution Research, vol. 27, no. 22, pp. 28042-28052, 2020.

[2] T. Shahnaz, V. Sharma, S. Subbiah, and S. Narayanasamy, "Multivariate optimisation of Cr (VI), Co (III) and Cu (II) adsorption onto nanobentonite incorporated nanocellulose/ chitosan aerogel using response surface methodology," Journal of Water Process Engineering, vol. 36, p. 101283, 2020.

[3] Y. El maguana, N. Elhadiri, M. Bouchdoug, M. Benchanaa, and A. Boussetta, "Optimization of preparation conditions of novel adsorbent from sugar scum using response surface methodology for removal of methylene blue," Journal of Chemistry, vol. 2018, Article ID 2093654, 10 pages, 2018.

[4] A. M. Elgarahy, K. Z. Elwakeel, G. A. Elshoubaky, and S. H. Mohammad, "Untapped sepia shell-based composite for the sorption of cationic and anionic dyes," Water, Air, \& Soil Pollution, vol. 230, p. 217, 2019.

[5] R. Kant, "Adsorption of dye eosin from an aqueous solution on two different samples of activated carbon by static batch method," Journal of Water Resource and Protection, vol. 4, no. 2, pp. 93-98, 2012.

[6] K. Z. Elwakeel, G. O. El-Sayed, and S. M. Abo El-Nassr, "Removal of ferrous and manganous from water by activated carbon obtained from sugarcane bagasse," Desalination and Water Treatment, vol. 55, no. 2, pp. 471-483, 2015.

[7] K. Ennaciri, A. Baçaoui, M. Sergent, and A. Yaacoubi, "Application of fractional factorial and Doehlert designs for optimizing the preparation of activated carbons from Argan shells," Chemometrics and Intelligent Laboratory Systems, vol. 139, pp. 48-57, 2014.

[8] K. Y. Foo and B. H. Hameed, "Mesoporous activated carbon from wood sawdust by $\mathrm{K}_{2} \mathrm{CO}_{3}$ activation using microwave heating," Bioresource Technology, vol. 111, pp. 425-432, 2012.

[9] A. Kausar, M. Iqbal, A. Javed et al., "Dyes adsorption using clay and modified clay: a review," Journal of Molecular Liquids, vol. 256, pp. 395-407, 2018.

[10] S. Babel, "Low-cost adsorbents for heavy metals uptake from contaminated water: a review," Journal of Hazardous Materials, vol. 97, no. 1-3, pp. 219-243, 2003.

[11] M. Besbes, N. Fakhfakh, and M. Benzina, "Characterization of silica gel prepared by using sol-gel process," Physics Procedia, vol. 2, no. 3, pp. 1087-1095, 2009.

[12] B. Sun and A. Chakraborty, "Thermodynamic frameworks of adsorption kinetics modeling: dynamic water uptakes on silica gel for adsorption cooling applications," Energy, vol. 84, pp. 296-302, 2015.

[13] S. K. Alpat, Ö. patref, Ş. Alpat, and H. Akçay, “The adsorption kinetics and removal of cationic dye, Toluidine Blue $\mathrm{O}$, from 
aqueous solution with Turkish zeolite," Journal of Hazardous Materials, vol. 151, no. 1, pp. 213-220, 2008.

[14] D. Caputo and F. Pepe, "Experiments and data processing of ion exchange equilibria involving Italian natural zeolites: a review," Microporous and Mesoporous Materials, vol. 105, no. 3, pp. 222-231, 2007.

[15] A. Wasti and M. Ali Awan, "Adsorption of textile dye onto modified immobilized activated alumina," Journal of the Association of Arab Universities for Basic and Applied Sciences, vol. 20, no. 1, pp. 26-31, 2016.

[16] K. Z. Elwakeel, "Removal of Reactive Black 5 from aqueous solutions using magnetic chitosan resins," Journal of Hazardous Materials, vol. 167, no. 1-3, pp. 383-392, 2009.

[17] K. Z. Elwakeel, A. A. El-Bindary, A. Ismail, and A. M. Morshidy, "Sorptive removal of Remazol Brilliant Blue $\mathrm{R}$ from aqueous solution by diethylenetriamine functionalized magnetic macro-reticular hybrid material," RSC Advances, vol. 6, no. 27, pp. 22395-22410, 2016.

[18] T. Shahnaz, C. Patra, V. Sharma, and N. Selvaraju, "A comparative study of raw, acid-modified and EDTA-complexed Acacia auriculiformis biomass for the removal of hexavalent chromium," Chemistry and Ecology, vol. 36, no. 4, pp. 360-381, 2020.

[19] C. Patra, R. M. N. Medisetti, K. Pakshirajan, and S. Narayanasamy, "Assessment of raw, acid-modified and chelated biomass for sequestration of hexavalent chromium from aqueous solution using Sterculia villosa Roxb. shells," Environmental Science and Pollution Research, vol. 26, no. 23, pp. 23625-23637, 2019.

[20] C. Patra, T. Shahnaz, S. Subbiah, and S. Narayanasamy, "Comparative assessment of raw and acid-activated preparations of novel Pongamia pinnata shells for adsorption of hexavalent chromium from simulated wastewater," Environmental Science and Pollution Research, vol. 27, no. 13, pp. 14836-14851, 2020.

[21] Y. El Maguana, N. Elhadiri, M. Bouchdoug, and M. Benchanaa, "Study of the influence of some factors on the preparation of activated carbon from walnut cake using the fractional factorial design," Journal of Environmental Chemical Engineering, vol. 6, no. 1, pp. 1093-1099, 2018.

[22] P. Ammendola, F. Raganati, and R. Chirone, " $\mathrm{CO}_{2}$ adsorption on a fine activated carbon in a sound assisted fluidized bed: thermodynamics and kinetics," Chemical Engineering Journal, vol. 322, pp. 302-313, 2017.

[23] F. Raganati, P. Ammendola, and R. Chirone, "On improving the $\mathrm{CO}_{2}$ recovery efficiency of a conventional TSA process in a sound assisted fluidized bed by separating heating and purging," Separation and Purification Technology, vol. 167, pp. 24-31, 2016.

[24] F. Raganati, P. Ammendola, and R. Chirone, "Role of acoustic fields in promoting the gas-solid contact in a fluidized bed of fine particles," KONA Powder and Particle Journal, vol. 32, pp. 23-40, 2015.

[25] K. Z. Elwakeel, M. A. Abd El-Ghaffar, S. M. El-kousy, and H. G. El-Shorbagy, "Synthesis of new ammonium chitosan derivatives and their application for dye removal from aqueous media," Chemical Engineering Journal, vol. 203, pp. 458-468, 2012.

[26] A. A. Yakout, M. A. Shaker, K. Z. Elwakeel, and W. Alshitari, "Lauryl sulfate@magnetic graphene oxide nanosorbent for fast methylene blue recovery from aqueous solutions," Journal of Dispersion Science and Technology, vol. 40, no. 5, pp. 707-715, 2019.

[27] I. A. W. Tan, A. L. Ahmad, and B. H. Hameed, "Preparation of activated carbon from coconut husk: optimization study on removal of 2,4,6-trichlorophenol using response surface methodology," Journal of Hazardous Materials, vol. 153, no. 1-2, pp. 709-717, 2008.

[28] J. Yang and K. Qiu, "Preparation of activated carbons from walnut shells via vacuum chemical activation and their application for methylene blue removal," Chemical Engineering Journal, vol. 165, no. 1, pp. 209-217, 2010.

[29] M. L. Martínez, M. M. Torres, C. A. Guzmán, and D. M. Maestri, "Preparation and characteristics of activated carbon from olive stones and walnut shells," Industrial Crops and Products, vol. 23, no. 1, pp. 23-28, 2006.

[30] P. Nowicki, R. Pietrzak, and H. Wachowska, "Sorption properties of active carbons obtained from walnut shells by chemical and physical activation," Catalysis Today, vol. 150, no. 1-2, pp. 107-114, 2010.

[31] T.-H. Liou, "Development of mesoporous structure and high adsorption capacity of biomass-based activated carbon by phosphoric acid and zinc chloride activation," Chemical Engineering Journal, vol. 158, no. 2, pp. 129-142, 2010.

[32] B. S. Girgis and M. F. Ishak, "Activated carbon from cotton stalks by impregnation with phosphoric acid," Materials Letters, vol. 39, no. 2, pp. 107-114, 1999.

[33] Y. El Maguana, N. Elhadiri, M. Bouchdoug, M. Benchanaa, and A. Jaouad, "Activated carbon from prickly pear seed cake: optimization of preparation conditions using experimental design and its application in dye removal," International Journal of Chemical Engineering, vol. 2019, Article ID 8621951, 12 pages, 2019.

[34] Y. El maguana, N. Elhadiri, M. Benchanaa, and R. Chikri, "Adsorption thermodynamic and kinetic studies of methyl orange onto sugar scum powder as a low-cost inorganic adsorbent," Journal of Chemistry, vol. 2020, Article ID 9165874, 10 pages, 2020.

[35] K. V. Kumar, "Linear and non-linear regression analysis for the sorption kinetics of methylene blue onto activated carbon," Journal of Hazardous Materials, vol. 137, no. 3, pp. 1538-1544, 2006.

[36] S. Lagergren, "Zur theorie der sogenannten adsorption gelöster stoffe, Kungliga Svenska Vetenskapsakademiens," Handlingar, vol. 24, pp. 1-39, 1898.

[37] Y. S. Ho and G. McKay, "Pseudo-second order model for sorption processes," Process Biochemistry, vol. 34, no. 5, pp. 451-465, 1999.

[38] A. G. Ritchie, "Alternative to the Elovich equation for the kinetics of adsorption of gases on solids," Journal of the Chemical Society, Faraday Transactions 1: Physical Chemistry in Condensed Phases, vol. 73, pp. 1650-1653, 1977.

[39] J. W. Weber and J. C. Morris, "Kinetics of adsorption on carbon from solution," Journal of the Sanitary Engineering Division, vol. 89, pp. 31-60, 1963.

[40] A. Gurses, C. Dogar, M. Yalcin, M. Acikyildiz, R. Bayrak, and S. Karaca, "The adsorption kinetics of the cationic dye, methylene blue, onto clay," Journal of Hazardous Materials, vol. 131, no. 1-3, pp. 217-228, 2006.

[41] G. B. Oguntimein, "Biosorption of dye from textile wastewater effluent onto alkali treated dried sunflower seed hull and design of a batch adsorber," Journal of Environmental Chemical Engineering, vol. 3, no. 4, pp. 2647-2661, 2015.

[42] G.-B. Hong and Y.-K. Wang, "Synthesis of low-cost adsorbent from rice bran for the removal of reactive dye based on the response surface methodology," Applied Surface Science, vol. 423, pp. 800-809, 2017.

[43] C. H. Giles, T. H. Macewan, S. N. Nakhwa, and D. Smith, “786. Studies in adsorption. Part XI. A system of classification of 
solution adsorption isotherms, and its use in diagnosis of adsorption mechanisms and in measurement of specific surface areas of solids," Journal of the Chemical Society (Resumed), vol. 10, pp. 3973-3993, 1960.

[44] I. Langmuir, "The constitution and fundamental properties of solids and liquids. Part I. Solids," Journal of the American Chemical Society, vol. 38, no. 11, pp. 2221-2295, 1916.

[45] H. Freundlish, "Over the adsorption in solution," Journal of Physical Chemistry, vol. 57, pp. 385-470, 1906.

[46] D. Kavitha and C. Namasivayam, "Experimental and kinetic studies on methylene blue adsorption by coir pith carbon," Bioresource Technology, vol. 98, no. 1, pp. 14-21, 2007.

[47] H. N. Tran, S.-J. You, and H.-P. Chao, "Thermodynamic parameters of cadmium adsorption onto orange peel calculated from various methods: a comparison study," Journal of Environmental Chemical Engineering, vol. 4, no. 3, pp. 26712682, 2016.

[48] T. A. Khan, E. A. Khan, and Shahjahan, "Removal of basic dyes from aqueous solution by adsorption onto binary ironmanganese oxide coated kaolinite: non-linear isotherm and kinetics modeling," Applied Clay Science, vol. 107, pp. 70-77, 2015.

[49] T. N. V. de Souza, S. M. L. de Carvalho, M. G. A. Vieira, M. G. C. da Silva, and D. d. S. B. Brasil, "Adsorption of basic dyes onto activated carbon: experimental and theoretical investigation of chemical reactivity of basic dyes using DFTbased descriptors," Applied Surface Science, vol. 448, pp. 662-670, 2018.

[50] S. Wang and Z. Zhu, "Effects of acidic treatment of activated carbons on dye adsorption," Dyes and Pigments, vol. 75, no. 2 , pp. 306-314, 2007.

[51] J. Ma, F. Yu, L. Zhou et al., "Enhanced adsorptive removal of methyl orange and methylene blue from aqueous solution by alkali-activated multiwalled carbon nanotubes," ACS Applied Materials \& Interfaces, vol. 4, no. 11, pp. 5749-5760, 2012.

[52] N. Mohammadi, H. Khani, V. K. Gupta, E. Amereh, and S. Agarwal, "Adsorption process of methyl orange dye onto mesoporous carbon material-kinetic and thermodynamic studies," Journal of Colloid and Interface Science, vol. 362, no. 2, pp. 457-462, 2011.

[53] D. Chen, J. Chen, X. Luan, H. Ji, and Z. Xia, "Characterization of anion-cationic surfactants modified montmorillonite and its application for the removal of methyl orange," Chemical Engineering Journal, vol. 171, no. 3, pp. 1150-1158, 2011.

[54] J. Liu, S. Ma, and L. Zang, "Preparation and characterization of ammonium-functionalized silica nanoparticle as a new adsorbent to remove methyl orange from aqueous solution," Applied Surface Science, vol. 265, pp. 393-398, 2013.

[55] S. Agarwal, I. Tyagi, V. K. Gupta et al., "RETRACTED: kinetics and thermodynamics of methyl orange adsorption from aqueous solutions-artificial neural network-particle swarm optimization modeling," Journal of Molecular Liquids, vol. 218, pp. 354-362, 2016.

[56] M. Ghaedi, A. M. Ghaedi, A. Ansari, F. Mohammadi, and A. Vafaei, "Artificial neural network and particle swarm optimization for removal of methyl orange by gold nanoparticles loaded on activated carbon and Tamarisk," Spectrochimica Acta Part A: Molecular and Biomolecular Spectroscopy, vol. 132, pp. 639-654, 2014.

[57] V. Yönten, N. K. Sanyürek, and M. R. Kivanç, "A thermodynamic and kinetic approach to adsorption of methyl orange from aqueous solution using a low cost activated carbon prepared from Vitis vinifera L," Surfaces and Interfaces, vol. 20, Article ID 100529, 2020.
[58] D.-M. Liu, C. Dong, J. Zhong, S. Ren, Y. Chen, and T. Qiu, "Facile preparation of chitosan modified magnetic kaolin by one-pot coprecipitation method for efficient removal of methyl orange," Carbohydrate Polymers, vol. 245, Article ID 116572, 2020.

[59] M. Hasan, M. M. Rashid, M. M. Hossain et al., "Fabrication of polyaniline/activated carbon composite and its testing for methyl orange removal: optimization, equilibrium, isotherm and kinetic study," Polymer Testing, vol. 77, Article ID 105909, 2019.

[60] L. Zhai, Z. Bai, Y. Zhu, B. Wang, and W. Luo, "Fabrication of chitosan microspheres for efficient adsorption of methyl orange," Chinese Journal of Chemical Engineering, vol. 26, no. 3, pp. 657-666, 2018. 